\title{
Phonological Awareness across Child Populations: How Bilingualism and Dyslexia Interact
}

\author{
Maria Vender*(D) and Chiara Melloni (D) \\ Department of Cultures and Civilizations, University of Verona, 37129 Verona, Italy; chiara.melloni@univr.it \\ * Correspondence: maria.vender@univr.it
}

check for

updates

Citation: Vender, Maria, and Chiara Melloni. 2021. Phonological Awareness across Child Populations: How Bilingualism and Dyslexia Interact. Languages 6: 39. https://doi.org/10.3390/ languages6010039

Received: 18 November 2020 Accepted: 20 February 2021 Published: 28 February 2021

Publisher's Note: MDPI stays neutral with regard to jurisdictional claims in published maps and institutional affiliations.

Copyright: (c) 2021 by the authors. Licensee MDPI, Basel, Switzerland. This article is an open access article distributed under the terms and conditions of the Creative Commons Attribution (CC BY) license (https:/ / creativecommons.org/licenses/by/ $4.0 /)$.

\begin{abstract}
Phonological awareness is a complex and multifaceted skill which plays an essential role in the development of an individual's language and literacy abilities. Phonological skills are indeed dramatically impaired in people with dyslexia, at any age and across languages, whereas their development in bilinguals is less clear. In addition, the interaction between bilingualism and dyslexia in this domain is still under-investigated. The aim of this paper is to provide new experimental evidence on this topic by exploring the phonological competence in Italian of monolingual and bilingual children with and without dyslexia. To this purpose, we developed three tasks, assessing nonword repetition, rhyme detection and spoonerisms, which we administered to 148 10-yearold children in two distinct studies. In Study 1, we found that two groups of L2 Italian typically developing bilinguals, having either Arabic or Romanian as L1, performed similarly to Italian monolinguals in all measures, pointing to absence of both bilingualism-related and L1-related effects in these tasks. In Study 2, we administered the same tasks to four groups of children: Italian monolinguals with dyslexia, Italian monolingual typically developing children, L2 Italian bilinguals with dyslexia and L2 Italian bilingual typically developing children. Results showed that children with dyslexia, both monolingual and bilingual, exhibited significantly more difficulties than typically developing children in all three tasks, whereas bilinguals, consistent with Study 1, performed similarly to their monolingual peers. In addition, no negative effects of bilingualism in dyslexia were found, indicating that being bilingual does not provide additional difficulties to children with dyslexia.
\end{abstract}

Keywords: phonological awareness; developmental dyslexia; bilingualism; bilingualism and dyslexia interaction; L2 children; nonword repetition; rhyme detection; spoonerisms

\section{Introduction}

Phonological Awareness (PA) refers to one's sensitivity to the sound structures of the language input. Specifically, it refers to the ability to identify, access and manipulate sound units such as syllables, phonemes, onsets and rhymes, and other suprasegmental units like tones (Blachman 1991; Wagner and Torgesen 1987). Therefore, far from being a monolithic construct, PA corresponds to an array of abilities involving access to and awareness of a range of sublexical elements, whose linguistic reality is often hidden by coarticulation. Indeed, PA is operationally measured by several different tests, each tapping a specific component, e.g., sound-to-word matching (e.g., "dog" starts with a /d/), word categorization on the basis of shared sounds (e.g., "dog" and "day" go together because they both start with /d/), phoneme blending (e.g., what does $[d-o-g]$ say?), phoneme segmentation of words or identification of (salient) segments of a word (e.g., what is the first sound in "dog"?), phoneme deletion (e.g., say "dog" without /d/), rhyme recognition (e.g., does "dog" rhyme with "fog"?), and other more complex manipulations, such as spoonerisms (e.g., Dog-Fine $\rightarrow$ Fog-Dine; Mann 1991; Savin 1972).

Together with phonological memory and processing skills, PA is a crucial component of phonological competence and it develops spontaneously throughout childhood. However, although children's sensitivity to sound structures emerges early (rudimentary skills 
are acquired in preschool years), PA is subject to constant refinement through early grades when, with literacy experience, children learn to associate graphic symbols with phonemes (see Melloni and Vender 2020 for a review).

In view of the tight relationship between phonological skills and literacy achievements, it is unsurprising that children with limited PA skills turn out to be candidates for reading difficulties (see Blachman 2000, and references within). Low awareness of sound structure often prevents mastery of reading in the first grades and these difficulties with letter-tosound decoding hinder vocabulary development and text comprehension, with the effect of negatively affecting or even prejudicing the child's educational path (Stanovich 1986). Therefore, a great deal of research has explored the phonological profile of children with dyslexia with the aim of identifying its characteristic deficits and designing more accurate tools for early diagnosis and intervention.

PA has been researched in the domain of bilingualism as well. Research on bilingual (especially early L2) children reports contrasting evidence on PA, as will be discussed more in Section 1.2; while several studies attest a bilingual advantage in PA tasks, others reveal disadvantages that have been attributed to the phonological complexity of the additional language, to its phonological distance from the L1, and/or its incomplete mastery in early L2 children. Therefore, more research on bilinguals' PA development is needed, especially in view of the central role of phonological skills for literacy achievement and of the difficulties in characterizing bilingual children's educational path.

Our research addresses phonological awareness skills in early L2 children ${ }^{1}$ and explores the interaction between bilingualism and dyslexia, which are both understudied areas, as will be discussed below. First of all, scarce is the experimental evidence on the effects of bilingualism in phonological and metaphonological skills, especially in L2 Italian. Even less explored is the relationship between the two conditions, bilingualism and dyslexia, in the phonological domain (with the notable exception of Vender et al. 2020), to the point that family, educators, and health professionals often fear that bilingualism can worsen the difficulties that children with dyslexia typically exhibit in this domain. Our first research goal was to assess the phonological profile of typically developing L2 children in Italian, while also evaluating the L1 influence on Italian L2 PA abilities. To this aim, in a first study, the performance of two groups of children with L1s being phonologically close or distant from Italian (i.e., Romanian and Arabic) has been compared to that of Italian monolingual children. This study is fundamental to address the second goal, that is, to disentangle the dimensions of bilingualism and dyslexia in the domain of phonological abilities. This issue has been explored in a second study in which both monolinguals and early L2 Italian children with and without dyslexia have been tested on the same PA tasks deployed in the first experiment.

The studies reported here have important implications for a better comprehension of the role of early exposure to a second language and of the effects of language (dis)similarity in L2 meta-phonological development. Moreover, an investigation of the interaction between bilingualism and dyslexia in phonological development could serve the purpose of designing more accurate tools for the diagnosis of reading deficits in bilinguals. While it is acknowledged that L2 children (as first- and second-generation immigrants) often experience school difficulties, this population is at risk of both under- and over-diagnosis of learning and language disorders, especially for the lack of assessment tools and norms for the bilinguals. In this light, it seems therefore crucial to carefully assess the bilingual children's phonological profile; whereas, as found in previous research on Italian, early L2 Italian children are expected to perform at the level of monolinguals in phonological tasks, marked deficits are expected to be found in monolingual and bilingual children with dyslexia. Therefore, PA could be fruitfully tested for the identification of reading deficits in bilingual children. In the following sections, we will report the main findings on

1 Early L2 children and bilingual children are definitions used interchangeably throughout the paper. Most children in the experimental studies have been exposed to Italian after two years of age and only a minority were exposed to Italian from birth (Vender et al. 2016). 
phonological awareness in dyslexia and bilingualism and we will explain the rationale and predictions for the present study.

\subsection{Phonological Awareness and Dyslexia}

As seen in the previous section, phonological awareness is a key language ability and a reliable predictor of reading achievement. Several studies have focused on the phonological skills of individuals with language impairments and found that a compromised phonological profile is common not only in the domain of language impairments but also in that of learning disabilities. In particular, phonological deficits are the hallmark of individuals suffering from developmental dyslexia, which is a highly specific impairment of reading and spelling ability occurring in people with an average or above average IQ, normal sensory acuity, and experience of appropriate educational instruction (World Health Organisation 1993). Currently, there is a large consensus on the Phonological Deficit Hypothesis according to which dyslexia is characterized by deficits in the representation, access, storage and manipulation of speech sounds (Bradley and Bryant 1983; Snowling 2000; Stanovich 1988; Vellutino 1979).

A solid body of research reports difficulties across all components of phonological representation and processing. PA skills are particularly limited in children with dyslexia, who underperform their typically developing peers in several tasks, such as phoneme manipulation, rhyme detection and spoonerisms (Bradley and Bryant 1978; Catts et al. 2005; Joanisse et al. 2000; Ramus et al. 2013). Moreover, it is acknowledged that people with dyslexia have poor verbal short-term memory, as measured by tasks such as digit span and nonword repetition (Snowling 2000; Szenkovits and Ramus 2005) and difficulties have been reported in speech perception and production (Adlard and Hazan 1998; Manis et al. 1997). Children with dyslexia are also slow at rapid automatized naming tasks, which measure speed of access to common words and their phonological forms (Denckla and Rudel 1976; Wolf and Bowers 2000). Indeed, some scholars have identified in a working memory inefficiency a core manifestation of dyslexia (Beneventi et al. 2010; Jeffries and Everatt 2004; Vender 2017).

Phonological deficits, however, are considered the main cause of disruption in reading processing and acquisition, since they prevent the child from establishing the solid phonological representation and awareness skills that are necessary for engaging in fast and accurate grapheme-to-phoneme decoding. These deficits are reported across different languages and ages, affecting preschoolers at risk of dyslexia, manifesting in early and later grades in school, and crucially persisting in adulthood, even when the reading deficits may have been compensated by the subject (Bruck 1992). Furthermore, phonological deficits are generally present in people with dyslexia and are responsible for the literacy impairment, as shown by Ramus et al. (2003). In this study a group of university students with and without dyslexia were tested on a range of phonological, visual and motor tasks, and it was found that participants with dyslexia underperformed their control peers in all phonological measures, including spoonerisms, rapid naming and nonword repetition, whereas only a subset presented additional motor and visual deficits. Ramus et al.'s study also showed that the phonological impairments associated with dyslexia are not transitory but persist through time, characterizing the linguistic profile of adults with dyslexia, too. As a matter of fact, longitudinal studies have evidenced that individuals with dyslexia do not simply lag behind their peers but manifest phonological impairments that emerge as the most distinctive trait of dyslexia across lifespan (Grivol and Hage 2011; Snowling et al. 1996).

Research has explored various domains of PA and has especially focused on those tasks that are more taxing for people with dyslexia, i.e., tasks requiring fine PA skills and/or high processing resources. As recent studies have shown, indeed, the difficulties experienced by children with dyslexia seem to derive not only from impaired phonological representations (Elbro 1996), but also from the cognitive skills necessary for accessing and manipulating these representations (Mundy and Carroll 2012; Ramus and Ahissar 2012; Ramus and Szenkovits 2008). Among the most inspected tasks of phonological processing and awareness in dyslexia are nonword repetition, rhyme detection and spoonerisms. 
Nonword repetition has been the investigation focus of several studies on children with language and learning impairments. This task requires the subject to repeat sequences of meaningless sound strings that are modeled after the phonotactic structure of the input language. Despite its apparent simplicity, nonword repetition involves short-term memory resources necessary to maintain the pseudowords in memory, but also phonological representation and awareness skills for creating acoustic representations and for supporting articulation. Major deficits in this task have been reported in children suffering from dyslexia, who underperformed both chronological-age- and reading-age-matched children as found in numerous studies (Kamhi and Catts 1986; Gathercole et al. 1994; Szenkovits and Ramus 2005; Tijms 2004; Cilibrasi et al. 2018; Melloni and Vender 2020; Vender et al. 2020) with constant results across the various languages tested (Paulesu et al. 2000). Difficulties are particularly severe as the length of the nonwords increases, probably related to the higher involvement of memory resources required, although they arise with shorter stimuli too (Couture and McCauley 2000). Moreover, it has been reported that performance in nonword repetition significantly correlates with literacy achievements (de Bree et al. 2010) and that this task could be employed to assist in the identification of dyslexia (Vender et al. 2020).

Another common measure of PA is rhyme detection, which relies on the ability to detect a shared suprasegmental unit among words, hence revealing the subject's sensitivity to global phonological similarity rather than to segmental units. While sensitivity to suprasegmental units emerges already in preschool years, rhyme detection has been found to be impaired in children with dyslexia, supporting the view that the source of the phonological impairment of dyslexia lies in the representation of prosodic units such as syllables and rhymes rather than of individual segments (Goswami 1999; Muter et al. 1998). Rhyme detection has been the research focus of Desroches et al. (2006), who administered an eye-tracking task to children with dyslexia with the aim of measuring phonological knowledge more directly and independently from extraneous factors such as attention, memory and metalinguistic abilities. Interestingly, they found that children with dyslexia diverge from their normally developing peers in the online processing of the phonological structure of rhymes, while other components of phonological competence are actually spared in these children. Furthermore, rhyme detection has been reported as a good predictor of reading acquisition in preschool children (Bryant et al. 1990).

Another challenging PA task for children with dyslexia is the spoonerism task, requiring the subjects to swap the initial sounds of two words, as in Fish-Boat $\rightarrow$ Bish-Foat (Landerl et al. 1997). In terms of PA skills, this task is not particularly complex since it requires segmentation at the level of onset and rhyme rather than that of individual segments. However, spoonerisms are especially taxing because they also require blending skills that need to be supported by short-term phonological memory and monitoring (Landerl and Wimmer 2000). In performing the task, indeed, the child has to keep the sound strings in memory and to monitor which segments have been blended and which ones still have to be assembled. Since it is acknowledged that phonological memory and processing resources are limited in children with dyslexia (Mundy and Carroll 2012; Ramus and Ahissar 2012; Ramus and Szenkovits 2008; Vender 2017) their low scores in spoonerisms are often explained as resulting from the high cognitive taxation of this task rather than from impairments in phonological knowledge. Indeed, the spoonerism task has been found very challenging for people with dyslexia (Knoop-van Campen et al. 2018; Walton and Brooks 1995).

Summarizing, phonological deficits have been reported in various domains of the phonological profile of people with reading impairments, with phonological memory and awareness emerging as especially compromised, negatively affecting their performance in various tasks and showing persistence across the lifespan. Crucially, a compromised phonological profile is an indicator of future reading deficits and its accurate assessment could assist early diagnosis of dyslexia. Furthermore, intervention studies focused on the rehabilitation of phonological abilities have been especially effective for both children (Blachman 2000; Bradley and Bryant 1983) and adults with dyslexia (Eden et al. 2004). This confirms the importance of a careful screening of the phonological abilities of children at 
risk of dyslexia and suggests the vital role that early intervention programs could play for assisting the child from the first steps in literacy.

\subsection{Phonological Awareness and Bilingualism}

A growing body of research over the last few decades has revealed benefits of bilingualism that extend from cognitive to (meta)linguistic abilities. In particular, it has been shown that early exposure to a second language makes children more aware of the arbitrariness of language and of the separation of content and form compared to their monolingual peers (Bialystok 1986, 2001). Furthermore, bilingualism prompts sensitivity to the structural commonalities and differences between their languages, making them more salient and allowing children to form more solid abstract language representations (Kuo and Anderson 2010). Bilinguals' enhanced metalinguistic awareness encompasses various linguistic levels; bilingual children, in particular, have more advanced word and syntactic awareness and usually show an advantage in morphological and phonological awareness too (Bialystok et al. 2014; Diaz 1985; Galambos and Goldin-Meadow 1990; Melloni and Vender 2020; Vender et al. 2021; Yelland et al. 1993).

Among the aspects of metalinguistic awareness, phonological awareness has received the most attention because of its connection to literacy development (Mann 1991; Blachman 2000). If a bilingual advantage were consistently found in this domain, it would imply that bilingual children could more easily acquire concepts of sublexical phonemic structure, with consequent advantages for early literacy acquisition. However, the results of the empirical studies on PA in bilinguals, often focusing on early L2 children, are mixed.

On the one hand, positive bilingual effects on PA have been observed among bilinguals speaking different pairs of languages, but limited to those cases where the additional language has more salient phonological features which might have facilitated the access to these features in both languages (Kuo and Anderson 2010). For instance, Campbell and Sais (1995) found that Italian-English bilingual children in kindergarten outperformed their English monolingual counterparts, who were slightly older, on a phonemic odd-one-out task and a syllable deletion task. The better results of the bilinguals were explained with the more regular syllable structure of Italian, which seems to have prompted the development of syllable structure awareness among Italian-English bilingual children. Comparable results have been reported by the longitudinal study of Bruck and Genesee (1995) who found that English-speaking children in a French immersion school outstated their peers in an English-speaking school in tasks of syllable awareness. This bilingual advantage was explained with the higher syllable salience of French, which seems to have enhanced syllable structure sensitivity in English too. Bruck and Genesee (1995) confirmed the results of the earlier study by Rubin and Turner (1989), who reported that 6-year-old Englishspeaking children in a French immersion program were better in phoneme segmentation than their counterparts in an English program. A similar bilingual advantage has been reported by Chen et al. (2004) who tested Mandarin-speaking monolingual children and Cantonese-Mandarin bilingual children on a series of odd-man-out tasks that measured their tone, onset, and rhyme awareness. In particular, bilingual children outstated their monolingual peers on tone awareness, which was attributed to the greater richness of tones in Cantonese.

These advantages have been mainly interpreted as the result of positive cross-language transfer, implying that the acquisition of particularly salient or complex features in the additional language can be transferred to the other language with less salient featural counterparts, thereby boosting the phonological awareness of the bilingual child compared to the monolingual child (Durgunoğlu et al. 1993). Beyond the role of cross-language transfer, another explanation of the bilingual advantage is offered by the Structural Sensitivity Theory (Kuo and Anderson 2010), according to which having access to two languages renders structural similarities and differences between languages more salient, thus allowing bilingual children to form representations of language structure at a more abstract level. Both explanations, i.e., cross-language transfer and the Structural Sensitivity Theory, 
are in line with the results of three meta-analyses on PA (Branum-Martin et al. 2012; Branum-Martin et al. 2015; Melby-Lervåg and Lervåg 2011) supporting the hypothesis that PA is a single, language-general construct across languages.

Other studies, however, have reported mixed or null results on PA development in bilinguals. For instance, in Bialystok et al. (2003) it was reported that bilingual children were no better than their monolingual peers in PA tasks like phoneme substitution or sound-meaning tasks. Only in phonemic segmentation did bilinguals show an advantage, but this was limited to the L1 Spanish and L2 English children; on the other hand, a disadvantage was found in the L1 Chinese and L2 English group, who underperformed their monolingual counterparts in this task. The contrast between the bilingual groups was explained with the similarity in sound structure between Spanish and English, whereas Chinese and English have more distant phonological structures. Similar results were indeed reported by Durgunoğlu et al. (1993), who found evidence for cross-language transfer of PA skills in L1-Spanish and L2-English bilinguals (kindergarten and Grade 1), and by Erdos et al. (2014) who found that L1 English and L2 French bilingual children's abilities in PA, phonological access, sentence repetition and letter-sound knowledge in their L1 could predict reading underachievement in the L2 and language difficulties in both L1 and L2. These empirical findings support the hypothesis that the phonological skills developed in one language can transfer to reading abilities in the other, suggesting that phonological skills constitute a unitary ability within and across languages.

Nonword repetition too is a well investigated ability in bilinguals, who are typically compared with monolinguals suffering from language impairments, since this task is considered a reliable clinical marker of Developmental Language Disorder (DLD; previously referred to as Specific Language Impairment). As with PA tasks, however, results are mixed and generally report no advantage or disadvantage of the bilinguals. Specifically, whereas typically developing bilinguals supersede monolinguals with DLD (Girbau and Schwartz 2008; Thordardottir and Brandeker 2013), studies that compared normally developing monolinguals and bilinguals have yielded conflicting evidence. For instance, Kohnert et al. (2006) reported a bilingual disadvantage in a study comparing L1 Spanish and L2 English with English monolinguals on a nonword repetition task modeled after English phonotactics. Similar results were reported in Messer et al. (2010) for L1 Turkish and L2 Dutch bilinguals tested in nonword repetition based on Dutch phonotactics. Vender et al. (2016) reported a monolingual performance in kindergarten bilinguals with Arabic, Albanian or Romanian as L1, tested on a nonword repetition task based on Italian phonotactics. A bilingual advantage, instead, was found by Tamburelli et al. (2015) comparing L1 Polish/L2 English and age-matched English monolinguals in a nonword repetition task modeled after English. This conflicting evidence can be explained with the complexity of the tested language's sound structure compared with that of the L1 of the bilinguals. Specifically, Tamburelli and colleagues proposed that the extremely high phonological complexity of Polish might have enhanced the mastery of a less phonologically complex language like English. This explanation could also account for the bilingual disadvantage reported by Kohnert et al. (2006) and Messer et al. (2010): in these cases, the tested languages, English and Dutch, had a more complex phonotactic structure than Spanish and Turkish respectively. Finally, the monolingual performance in nonword repetition of L2 Italian bilinguals could be ascribed to the phonotactic simplicity of this language, characterized by a salient syllabic and phonemic structure.

Summarizing, the evidence collected thus far suggests that bilingualism per se does not negatively influence PA development: bilinguals often show monolingual performance or do better than monolinguals in PA and nonword repetition tasks, a result mainly attributed to the cross-linguistic transfer of phonological competence from the L1 to the additional language. However, a bilingual disadvantage has also been reported and explained with the imperfect mastery of the L2, especially in cases where the tested language had a more complex phonological system than that of the L1. 


\subsection{Research Questions, Rationale and Predictions}

As discussed above, phonological abilities and especially phonemic awareness play a vital role not only in children's language development but also in literacy acquisition. Due to the severe phonological impairment consistently found in individuals with dyslexia and to the conflicting results reported in bilinguals, exploring the interaction between bilingualism and dyslexia in the phonological domain is of major importance. With the purpose of shedding light on these aspects, we developed two distinct studies targeting specific research questions and assessing phonological awareness in distinct populations by means of the same three tasks addressing nonword repetition, rhyme detection and spoonerisms. These three tasks were chosen as they provide a broad assessment of the individual's phonological awareness, with a different involvement of working memory resources, which, as discussed above, are arguably higher in the spoonerism task.

In Study 1, we first aimed to investigate the phonological awareness of bilingual children with L2 Italian comparing their performance to that of monolingual Italian children, while also considering possible effects related to the distance between L1 and L2. To this aim, we compared the phonological awareness of monolingual Italian children to those of two groups of bilingual L2 Italian children, having either Romanian or Arabic as their first language. These two languages were chosen in relation to their closeness to Italian from the phonological point of view. Romanian and Italian belong to the same Romance language family and they share strong similarities at the phonological level (Galatà et al. 2020; Topoliceanu 2011), whereas Arabic belongs to the Semitic family and presents a phonological system of greater complexity (Watson 2007). Comparing the performance of the two groups of bilinguals to that of monolingual Italian speakers allowed us to verify whether the phonological distance affects performance in PA tasks; based on what was reported above and on the fact that Italian has a simple phonotactic system, no differences were expected between the three groups.

Since this prediction was confirmed by the results of Study 1, which highlighted the absence of differences between the two bilingual groups and the monolinguals, we conducted a second study with the core purpose of investigating phonological awareness in L2 Italian bilingual children with and without a diagnosis of dyslexia. In this case, due to the difficulties of finding a sufficiently large number of bilingual children with dyslexia speaking the same L1, we included children having different L1 backgrounds and compared them with two groups of monolinguals, both typically developing children and suffering from dyslexia. Since phonology is severely deficient in dyslexia, higher and comparable difficulties were expected in the two groups with dyslexia than in the control groups; moreover, by comparing bilingual children with and without impairments to their monolingual peers we aimed to explore the effects of bilingualism on dyslexia in the phonological domain, an issue that has been under-investigated so far. Furthermore, we were interested in analyzing whether performance in the three PA tasks correlated with vocabulary and working memory measures and whether the four groups of children differed in this respect.

\section{Materials and Methods}

2.1. Study 1

\subsubsection{Participants}

The study was administered to 40 participants divided in three groups: 15 L1 Arabic and L2 Italian bilingual children (ARA; mean age: 10.04 years old, Standard Deviation $=1.36$ ), 10 L1 Romanian L2 Italian bilingual children (ROM; 10.39 y.o., SD = 1.24) and 15 monolingual Italian children ( $\mathrm{MON} ; 9.57$ y.o., $\mathrm{SD}=0.94)$. No age differences were found among the three groups $(F(2,37)=1.494, p=0.238)$.

Both monolingual and bilingual children were recruited in the same public schools in the area of Trento and Verona (Northern Italy); none of them had diagnosed nor referred cognitive deficits, language or learning problems, hearing disorders or reading difficulties, 
according to teacher and parental reports. In addition, all children had normal or correctedto-normal vision.

By means of a questionnaire filled in by parents, we verified that all bilinguals were active speakers of both languages and that they used them on a regular basis; the L1 was mainly spoken at home, while the L2 was used at school and in extracurricular activities. All bilingual children were exposed to their L1 at birth and to Italian before age 6, and they had at least three years of consecutive attendance to the primary school in Italy. The average Age of Exposure to Italian was balanced among the two bilingual groups, being 2.64 years old for ARA children $(\mathrm{SD}=2.20$; range: $0-5.10$ years, 3 children exposed to Italian from birth) and 2.88 for $\mathrm{ROM}(\mathrm{SD}=1.60$; range: $0-5.91$ years, 2 children exposed to Italian from birth; $t(23)=0.317, p=0.754)$, as well as the Traditional Length of Exposure, measured as the subjects' chronological age minus their age of first exposure, which was 7.33 years for ARA $(\mathrm{SD}=2.45$; range: $3.4-11.68)$ and 7.88 years for $\mathrm{ROM}(\mathrm{SD}=2.39$; range: 4.84-11.97; $t(23)=0.557, p=0.583)$.

Participants were individually tested in a quiet room; they were first administered a series of preliminary tasks to provide a detailed profile of their language and reading skills, and then three experimental tasks assessing nonword repetition, rhyme detection and spoonerisms, as will be described in more detail below. The administration of the whole protocol lasted around $60 \mathrm{~min}$.

The study was approved by the local ethics committee and conducted in accordance with the standards specified in the 2013 Declaration of Helsinki; informed written consent was obtained for all participants.

\subsubsection{Preliminary Measures}

All groups of children were administered a set of preliminary tasks which contributed to determine their linguistic and cognitive profile, before being presented with the three experimental tasks assessing their phonological competence. Both preliminary measures and phonological tasks administered in Study 1 were used in Study 2 as well.

We administered the CPM Raven task to have a measure of the subject's nonverbal intelligence (Raven et al. 1998; Belacchi et al. 2008) and the word and nonword reading subtests of the Batteria per la Valutazione della Dislessia e della Disortografia Evolutiva (DDE-2, Sartori et al. 2007) to assess their reading abilities. The DDE-2 is a standardized task used to evaluate children's reading skills in Italian; in the two sub-tests that we administered, participants were asked to read aloud respectively a set of 112 Italian words, varying in frequency and orthographic complexity, and 48 nonwords. Both accuracy and reading times were measured. As inclusion criteria, children had to score higher than 1.5 SD below the mean of their age range in both cognitive and reading tasks. Finally, to have a measure of the children's receptive vocabulary in Italian, we administered the Italian standardization of the PPVT-R (Dunn and Dunn 2000).

\subsubsection{Nonword Repetition Task}

To assess the participant's ability to repeat invented words modeled after the Italian phonotactic rules we administered an original nonword repetition task (see Vender et al. 2020 for a detailed description of the test), composed of 40 nonwords which were carefully designed following (Dollaghan and Campbell 1998) and manipulating both length, which ranged from 2 to 5 syllables, and complexity, using syllables with different levels of complexity (CV, CVC, CCV, CCVC, CVVC) taken from an Italian syllable frequency database (Stella and Job 2001). The nonwords, which were recorded by a female native speaker of Italian and played through loudspeakers connected to a laptop, were presented randomized, preceded by two training items. The task was preceded by two training trials to let children familiarize themselves with the test. As in Vender et al. (2020), 1 point was attributed to correct repetitions considering the stimulus as a whole, whereas 0 points were given to incorrect repetitions, independent of the number of errors committed in a single nonword. 


\subsubsection{Rhyme Detection Task}

Before administering this task, the experimenter made sure that children knew what a rhyme was, providing a simple explanation if necessary. The task was composed by 2 training items, in which children were provided with feedback to assure that they had understood the task, and 10 experimental items in which no feedback was given. In each trial, the participant was presented with an array of four pictures corresponding to four different words, which appeared one at a time on a computer screen and which were pronounced aloud by the experimenter. Each trial comprised a given word (e.g., forchetta "fork") and three test words: a word rhyming with the given word (rhyme; e.g., molletta, "clothspin"), a word with the same onset of the given word (phonological distractor; e.g., formaggio, "cheese") and a word belonging to the same semantic area of the given word (semantic distractor; e.g., coltello, "knife"). The subject's task was to identify the test word that rhymed with the given word. Only three-syllable words with stress on the penultimate syllable were used; this syllable length has been chosen as it is highly representative in Italian and suitable for a rhyme detection task. Finally, we controlled the frequency of the words used in the task, including only frequent and concrete words to avoid possible lexical effects that could penalize bilinguals, in relation to their generally poorer vocabulary ( Bialystok et al. 2010). One point was attributed if the rhyming word was correctly identified, 0 points otherwise.

\subsubsection{Spoonerism Task}

In this task, children were orally presented with two two-syllable words (e.g., cane "dog" and rosa "rose") and were asked to swap the first sound of each word to obtain two different existing words (e.g., rane "frogs" and cosa "thing"). There were three practice trails in which the participants could familiarize themselves with the task and were given feedback, and 10 experimental trials. All given words were composed of two syllables; half the stimuli consisted of two simple syllables and half of one simple syllable and one complex syllable. Two points were attributed if both words were correctly produced, 1 point if only one word was correctly produced and 0 points in cases where no correct answer was produced.

\subsection{Study 2}

\subsubsection{Participants}

Our second study aimed to verify how bilingualism and dyslexia interact in tasks assessing phonological awareness. The same measures employed in Study 1 were administered to 108 participants divided in four groups: 24 Italian monolingual children with a diagnosis of dyslexia (MD; mean age: 10.18 y.o., $S D=1.16$ ), 30 Italian monolingual typically developing children (MC; 9.99 y.o., 0.99), 24 bilingual L2 Italian children with a diagnosis of dyslexia (BD; 10.35, SD = 1.36) and 30 bilingual L2 Italian typically developing children $(B C=10.21, S D=1.20)$. No age differences were found among groups $F(3,104)=0.429$, $p=0.733)$. All children attended the same public schools in the area of Trento and Verona (Northern Italy); some of these children also took part in Vender et al. (2020)'s study.

All children with dyslexia had independently received a diagnosis by a team of health professionals within the local Italian Health Care System based on standard criteria (ICD-10, F 81.0; World Health Organization 2004); they had no additional hearing, visual deficits or comorbidities with language disorders. Children presenting comorbidities with language disorders (DLD) as well as children displaying or having displayed language delays or deficits according to parental or teachers reports were not included in the study, in order to minimize possible confounding effects on the results related to the presence of specific language impairments.

All control children were typically developing, with no physical, language, reading or learning deficits according to teacher and parental reports.

All bilingual children had Italian as a second language and used their L1 in the domestic environment; in this study, we included children with different L1s, due to difficulties 
in finding a sufficiently representative group of L2 Italian children with a diagnosis of dyslexia. However, precise information about their exposure to L1 and L2 was collected by administering the Bilingual Language Exposure Questionnaire (see Vender et al. 2016 for a description of the questionnaire adapted to Italian from Unsworth et al. 2014). Age of first exposure was balanced among the two groups: BD were first exposed to Italian on average at age 2.5 ( $\mathrm{SD}=2.30$; range: $0-5.68 ; 7$ children exposed to Italian from birth) and $\mathrm{BC}$ at age $2.22(\mathrm{SD}=1.84, t(50)=0.538 p=0.593$; range: $0-5.91 ; 9$ children exposed to Italian from birth). Both groups had a higher current quantity of exposure to Italian: the rate of L2 exposure was 0.67 for $\mathrm{BD}(\mathrm{SD}=0.14)$ and 0.65 for $\mathrm{BC}(\mathrm{SD}=0.14, t(50)=0.529, p=0.599)$. Traditional length of exposure was similar between the two groups too (BD: 7.71 years, $\mathrm{SD}=2.20$; $\mathrm{BC}$ : $8.18, \mathrm{SD}=2.08, t(50)=0.785 p=436)$ as well as the cumulative length of exposure, i.e., a more precise measure that takes into account the different linguistic experiences of each bilingual throughout their life (BD: 2.27 years, $\mathrm{SD}=0.81 ; \mathrm{BC}: 2.42, \mathrm{SD}=0.75, t(50)=0.646, p=0.521$ ).

All participants were individually tested in a quiet room; the administration of the whole protocol lasted around $60 \mathrm{~min}$. The study was approved by the local ethics committee and conducted in accordance with the standards specified in the 2013 Declaration of Helsinki; informed written consent was obtained for all participants.

\subsubsection{Preliminary Measures}

All participants were administered the same preliminary measures used in Study 1 to assess their nonverbal intelligence, receptive vocabulary and reading abilities. As inclusion criteria, all children had to score within the normal range $(>1.5 \mathrm{SD}$ below the mean for their age) in the CPM Raven; reading abilities had to be higher than 1.5 SD below the mean for their age for the typically developing children, and lower than 2 SD for the children with dyslexia in at least two measures in accuracy and/or speed of word and nonword reading. In addition, participants were administered a Forward Digit Span task (FDS) and a Backward Digit Span task (BDS), two working memory tasks addressing different working memory components. Adopting Baddeley's Working Memory Model (Baddeley 2001), in the FDS the subjects' phonological memory (specifically, the Phonological Loop) is tackled, since they are asked to temporarily maintain an acoustic representation of the orally presented sequence of digits. The BDS, instead, is a more complex task since subjects are not only asked to memorize sequences of orally presented digits, but also to repeat them in the reverse order (e.g., 3-6-4 has to be repeated as 4-6-3). In this case, thus, phonological short-term memory skills are required to temporarily maintain in memory the sequence of digits uttered by the experimenter, but manipulation abilities are also involved to repeat the sequence in the reverse order, with and involvement, in Baddeley's model, of both Phonological Loop and Central Executive. The two tasks were taken from the Working Memory Test Battery for Children (Pickering and Gathercole 2001; see Vender 2017 for further details about the task). In both FDS and BDS, the stimuli to be recalled belonged to blocks of increasing length (starting with 2 digits) consisting of 6 items for each length. All digits were uttered in a monotone voice at the rate of 1 per second. If the first four trials of one block were correctly recalled, the fifth and the sixth were skipped, and the child was immediately presented with the subsequent block. Testing stopped when three errors were committed within the same block. The subject's span corresponded to the last block correctly recalled.

\subsubsection{Phonological Awareness Tasks}

The same three tasks presented above and assessing nonword repetition, rhyme detection and spoonerisms were administered to each participant, adopting the same procedures and scoring systems used in Study 1 . 


\section{Results}

\subsection{Study 1}

\subsubsection{Preliminary Measures}

Means and SDs of the three groups in the preliminary tasks administered are reported in Table 1. A series of one-way ANOVAs with Group (MON; ARA; ROM) as independent variable and each measure as dependent variable were run to verify whether there were statistically significant differences among the three groups. No differences were reported in the CPM Raven Task $\left(F(2,37)=0.72, p=0.495\right.$, partial $\left.\eta^{2}=0.04\right)$. As for reading, a significant difference was found in the accuracy of word reading $(F(2,37)=2.820, p=0.014$, partial $\eta^{2}=0.21$ ), with both ARA and ROM scoring lower than MON (ARA vs. ROM: $\mathrm{M}_{\text {difference }}=-0.74, \mathrm{p}=0.035,95 \%$ C.I. $[-1.45,-0.40] ; \mathrm{ROM}$ vs MON: $\mathrm{M}_{\text {difference }}=-0.82$, $p=0.039,95 \%$ C.I. $[-1.61,-0.03]$ ), whereas no differences were found between ARA and $\operatorname{ROM}\left(\mathrm{M}_{\text {difference }}=-0.08, p=1.000,95 \%\right.$ C.I. $\left.[-0.71,0.86]\right)$. No differences were found in the other reading measures: word reading speed $\left(F(2,37)=0.10, p=0.901\right.$, partial $\left.\eta^{2}=0.01\right)$, nonword reading speed $\left(F(2,37)=0.89, p=0.42\right.$, partial $\left.\eta^{2}=0.05\right)$ and nonword reading accuracy $\left(F(2,37)=0.24, p=0.78\right.$, partial $\left.\eta^{2}=0.01\right)$. Significant differences were found instead in receptive vocabulary, measured by the PPVT-R $(F(2,37)=9.68, p<0.001$, partial $\left.\eta^{2}=0.34\right)$; specifically, ARA scored significantly lower than $\mathrm{MON}\left(\mathrm{M}_{\text {difference }}=-18.73\right.$, $p<0.001,95 \%$ C.I. [ $-29.52,-7.95])$, whereas only a marginal significance was found between ARA and ROM ( $\mathrm{M}_{\text {difference }}=-12.03, p=0.051,95 \%$ C.I. [ $\left.\left.-24.09,0.02\right]\right)$, who in turn did not differ from $\mathrm{MON}\left(\mathrm{M}_{\text {difference }}=-6.70, p=0.515,95 \%\right.$ C.I. $\left.[-5.36,18.76]\right)$.

Table 1. Means (SDs) of the three groups in the preliminary measures.

\begin{tabular}{ccccccc}
\hline Group & CPM Raven & $\begin{array}{c}\text { Word } \\
\text { Reading } \\
\text { Speed }\end{array}$ & $\begin{array}{c}\text { Word } \\
\text { Reading } \\
\text { Errors }\end{array}$ & $\begin{array}{c}\text { Nonword } \\
\text { Reading } \\
\text { Speed }\end{array}$ & $\begin{array}{c}\text { Nonword } \\
\text { Reading } \\
\text { Errors }\end{array}$ & PPVT-R \\
\hline MON & $0.39(0.89)$ & $0.24(0.93)$ & $0.96(0.38)$ & $0.18(0.86)$ & $0.26(0.68)$ & $104.40(9.81)$ \\
ARA & $0.04(0.60)$ & $0.10(0.68)$ & $0.22(0.94)$ & $0.51(0.56)$ & $0.20(0.49)$ & $85.67(10.86)$ \\
ROM & $0.23(0.95)$ & $0.16(1.01)$ & $0.14(0.91)$ & $0.45(0.62)$ & $0.40(0.99)$ & $97.70(15.39)$ \\
\hline
\end{tabular}

Notes: MON = Monolingual children; ARA = Arabic L1 children; ROM = Romanian L1 children. Z-scores are reported for the CPM Raven task and the reading tasks; raw scores are reported for the PPVT-R.

\subsubsection{Phonological Awareness Tasks}

The results of the three tasks assessing the participants' phonological awareness are reported in Table 2.

Table 2. Mean accuracy (SDs) of the three groups in the phonological tasks.

\begin{tabular}{cccc}
\hline Group & Nonword Repetition & Rhyme Detection & Spoonerisms \\
\hline MON & $0.89(0.05)$ & $0.91(0.11)$ & $0.73(0.18)$ \\
ARA & $0.91(0.05)$ & $0.87(0.16)$ & $0.77(0.16)$ \\
ROM & $0.92(0.05)$ & $0.97(0.07)$ & $0.74(0.21)$ \\
\hline
\end{tabular}

Notes: MON = Monolingual children; ARA = Arabic L1 children; ROM = Romanian L1 children.

As revealed by the data, all groups of children showed a very good performance in the three tasks, with accuracy rates being lower in the spoonerism task, the most difficult one, although similar among groups. This was confirmed by the statistical analysis, reporting absence of significant differences in nonword repetition $(F(2,37)=1.04, p=0.364$, partial $\left.\eta^{2}=0.05\right)$, rhyme detection $\left(F(2,37)=1.80, p=0.180\right.$, partial $\left.\eta^{2}=0.09\right)$ and spoonerisms $\left(F(2,37)=0.254, p=0.78\right.$, partial $\left.\eta^{2}=0.01\right)$. This indicates that bilingualism did not affect the phonological awareness of L2 Italian children, who performed similarly to their monolingual peers; in addition, the absence of differences found between the two bilingual groups suggests that the L1 does not affect performance in phonological awareness tasks. 


\subsection{Study 2}

\subsubsection{Preliminary Measures}

Results of the preliminary measures are displayed in Table 3. In case of significant group effects, post-hoc comparisons with Bonferroni correction were run.

Table 3. Means (SDs) of the three groups in the preliminary measures.

\begin{tabular}{|c|c|c|c|c|c|c|c|c|}
\hline Group & $\begin{array}{c}\text { CPM } \\
\text { Raven }\end{array}$ & $\begin{array}{c}\text { Word } \\
\text { Reading } \\
\text { Speed }\end{array}$ & $\begin{array}{l}\text { Word } \\
\text { Reading } \\
\text { Errors }\end{array}$ & $\begin{array}{c}\text { Nonword } \\
\text { Reading } \\
\text { Speed }\end{array}$ & $\begin{array}{c}\text { Nonword } \\
\text { Reading } \\
\text { Errors }\end{array}$ & PPVT-R & FDS & BDS \\
\hline MD & $\begin{array}{c}0.03 \\
(0.75)\end{array}$ & $\begin{array}{l}-3.70 \\
(2.72)\end{array}$ & $\begin{array}{l}-2.22 \\
(1.82)\end{array}$ & $\begin{array}{l}-2.74 \\
(2.49)\end{array}$ & $\begin{array}{l}-2.01 \\
(1.34)\end{array}$ & $\begin{array}{c}109.17 \\
(12.14)\end{array}$ & $\begin{array}{l}25.00 \\
(3.71)\end{array}$ & $\begin{array}{c}9.74 \\
(4.16)\end{array}$ \\
\hline $\mathrm{MC}$ & $\begin{array}{c}0.40 \\
(0.80)\end{array}$ & $\begin{array}{c}0.24 \\
(0.63)\end{array}$ & $\begin{array}{c}0.28 \\
(0.87)\end{array}$ & $\begin{array}{c}0.26 \\
(0.61)\end{array}$ & $\begin{array}{c}0.27 \\
(0.80)\end{array}$ & $\begin{array}{l}105.90 \\
(9.35)\end{array}$ & $\begin{array}{l}28.67 \\
(4.57)\end{array}$ & $\begin{array}{l}13.03 \\
(4.24)\end{array}$ \\
\hline $\mathrm{BD}$ & $\begin{array}{c}0.12 \\
(0.58)\end{array}$ & $\begin{array}{l}-2.13 \\
(2.18)\end{array}$ & $\begin{array}{l}-2.71 \\
(1.32)\end{array}$ & $\begin{array}{l}-0.88 \\
(1.45)\end{array}$ & $\begin{array}{l}-2.29 \\
(1.10)\end{array}$ & $\begin{array}{c}90.08 \\
(13.33)\end{array}$ & $\begin{array}{l}23.91 \\
(3.48)\end{array}$ & $\begin{array}{l}10.33 \\
(3.60)\end{array}$ \\
\hline $\mathrm{BC}$ & $\begin{array}{c}0.18 \\
(0.83)\end{array}$ & $\begin{array}{c}0.22 \\
(0.80)\end{array}$ & $\begin{array}{c}0.03 \\
(0.95)\end{array}$ & $\begin{array}{c}0.61 \\
(0.69)\end{array}$ & $\begin{array}{c}0.18 \\
(0.83)\end{array}$ & $\begin{array}{l}95.70 \\
(9.35)\end{array}$ & $\begin{array}{l}27.60 \\
(6.61)\end{array}$ & $\begin{array}{l}13.47 \\
(5.33)\end{array}$ \\
\hline
\end{tabular}

Notes: MD = Monolingual children with Dyslexia; MC = Monolingual Controls; BD = Bilingual children with Dyslexia; $\mathrm{C}=$ Bilingual Controls. Z-scores are reported for the CPM Raven task and the reading tasks; raw scores are reported for the PPVT-R, the FDS and the BDS.

No differences were found among the four groups in the CPM Raven $(F(3,104)=1.22$, $p=0.31$, partial $\eta^{2}=0.03$ ).

As for reading, significant group differences were found in the four measures considered. In word reading speed $\left(F(3,104)=32.80, p<0.001\right.$, partial $\left.\eta^{2}=0.49\right)$, post-hoc comparisons showed that both groups with dyslexia performed worse than the two control groups (BD vs. $\mathrm{BC}$ : $\mathrm{M}_{\text {difference }}=-2.35, p<0.001,95 \%$ C.I. $[-3.62,-1.08]$; $\mathrm{BD}$ vs. $\mathrm{MC}$ : $\mathrm{M}_{\text {difference }}=-2.37, p<0.001,95 \%$ C.I. $[-3.64,-1.10] ; \mathrm{MD}$ vs. $\mathrm{BC}: \mathrm{M}_{\text {difference }}=-3.917$, $p<0.001,95 \%$ C.I. $[-5.19,-2.65]$; MD vs. MC: $\mathrm{M}_{\text {difference }}=-3.93, p<0.001,95 \%$ C.I. $[-5.20,-2.66]) . \mathrm{MC}$ and $\mathrm{BC}$ showed instead a similar performance $\left(\mathrm{M}_{\text {difference }}=0.015\right.$, $p=1.000,95 \%$ C.I. $[-1.21,1.18])$; in addition, BD were significantly faster than MD $\left(\mathrm{M}_{\text {difference }}=1.56, p=0.013,95 \%\right.$ C.I. $\left.[0.22,2.90]\right)$.

In word reading accuracy $\left(F(3,104)=39.311, p<0.001\right.$, partial $\left.\eta^{2}=0.531\right)$, BD and $\mathrm{MD}$ scored lower than their peers (BD vs. BC: $\mathrm{M}_{\text {difference }}=-2.74, p<0.001,95 \%$ C.I. [ -3.67 , $-1.82]$; $\mathrm{BD}$ vs. $\mathrm{MC}$ : $\mathrm{M}_{\text {difference }}=-2.989, p<0.001,95 \%$ C.I. $[-3.92,-2.06]$; $\mathrm{MD}$ vs. BC: $\mathrm{M}_{\text {difference }}=-2.25, p<0.001,95 \%$ C.I. $[-3.17,-1.32]$; $\mathrm{MD}$ vs. $\mathrm{MC}: \mathrm{M}_{\text {difference }}=-2.494$, $p<0.001,95 \%$ C.I. $[-3.42,-1.57])$; no differences were found between $\mathrm{MD}$ and $\mathrm{BD}\left(\mathrm{M}_{\text {difference }}\right.$ $=0.50, \mathrm{p}=1.000,95 \%$ C.I. $[-0.48,1.47])$ nor between $\mathrm{MC}$ and BC $\left(\mathrm{M}_{\text {difference }}=0.25, p=1.000\right.$, $95 \%$ C.I. $[-0.63,1.12])$.

In nonword reading speed $\left(F(3,104)=28.50, p<0.001\right.$, partial $\left.\eta^{2}=0.45\right)$, MD were significantly slower than the other three groups (MD vs BD: $\mathrm{M}_{\text {difference }}=-1.86, p<0.001$, $95 \%$ C.I. $[-2.98,-0.74]$; MD vs. MC: $\mathrm{M}_{\text {difference }}=-2.99, p<0.001,95 \%$ C.I. [ -4.06 , $-1.93]$; $\mathrm{MD}$ vs. $\mathrm{BC}: \mathrm{M}_{\text {difference }}=3.35, p<0.001,95 \%$ C.I. [ $\left.-4.41,-2.29\right]$ ), whereas BD performed worse than $\mathrm{MC}\left(\mathrm{M}_{\text {difference }}=-1.14, p=0.029,95 \%\right.$ C.I. $[-2.20,-0.07)$ and $\mathrm{BC}\left(\mathrm{M}_{\text {difference }}=-1.49, p=0.002,95 \%\right.$ C.I. $[-2.55,-0.43)$; no differences were found between $\mathrm{MC}$ and $\mathrm{BC}\left(\mathrm{M}_{\text {difference }}=-0.354, p=1.000,95 \%\right.$ C.I. $\left.[-1.36,0.65]\right)$.

Finally, in nonword reading accuracy $\left(F(3,104)=48.48, p<0.001\right.$, partial $\left.\eta^{2}=0.58\right)$, $\mathrm{MD}$ and $\mathrm{BD}$ performed worse than the two control groups (BD vs. $\mathrm{BC}: \mathrm{M}_{\text {difference }}=-2.46$, $p<0.001,95 \%$ C.I. $[-3.21,-1.71] ; \mathrm{BD}$ vs. MC: $\mathrm{M}_{\text {difference }}=-2.56, p<0.001,95 \%$ C.I. [ -3.31 , $-1.81]$; MD vs. BC: $\mathrm{M}_{\text {difference }}=-2.18, p<0.001,95 \%$ C.I. [ $\left.-2.93,-1.43\right]$; MD vs. MC: $\mathrm{M}_{\text {difference }}=-2.28, p<0.001,95 \%$ C.I. [ $\left.\left.-3.03,-1.53\right]\right)$. No differences were found between $\mathrm{MD}$ and $\mathrm{BD}\left(\mathrm{M}_{\text {difference }}=0.28, p=1.000,95 \%\right.$ C.I. $[-1.07,-0.51)$ or between $\mathrm{MC}$ and $\mathrm{BC}$ $\left(\mathrm{M}_{\text {difference }}=0.10, p=1.000,95 \%\right.$ C.I. $\left.[-0.61,0.81]\right)$.

Highly significant differences were reported in vocabulary too $(F(3,104)=13.55$, $p<0.001$, partial $\eta^{2}=0.28$ ); in this case, both groups of bilinguals performed less accurately than both groups of monolinguals (BD vs. MD: $\mathrm{M}_{\text {difference }}=-19.08, p<0.001$, $95 \%$ C.I. $[-28.49,-9.68]$; BD vs. MC: $\mathrm{M}_{\text {difference }}=-15.817, p<0.001,95 \%$ C.I. [ -24.74 , $-6.89]$; $\mathrm{BC}$ vs. $\mathrm{MD}$ : $\mathrm{M}_{\text {difference }}=-13.47, p=0.001,95 \%$ C.I. [ $\left.-22.39,-4.54\right]$; $\mathrm{BC}$ vs. MC: 
$\mathrm{M}_{\text {difference }}=-10.200, p=0.009,95 \%$ C.I. $\left.[-18.62,-1.79]\right)$, whereas no differences were found between the $\mathrm{MC}$ and $\mathrm{MD}\left(\mathrm{M}_{\text {difference }}=-3.27, p=1.000,95 \%\right.$ C.I. $\left.[-12.19,5.66]\right)$ or between the BC and BD ( $\mathrm{M}_{\text {difference }}=5.617, p=0.561,95 \%$ C.I. $\left.[-3.31,14.54]\right)$.

Group was significant in the two WM tasks as well: in $\operatorname{FDS}(F(3,103)=5.443$, $p<0.002$, partial $\left.\eta^{2}=0.14\right)$, post-hoc comparisons with Bonferroni correction showed that BD scored lower than BC $\left(\mathrm{M}_{\text {difference }}=-3.68, p=0.042,95 \%\right.$ C.I. [-7.28, -0.81$\left.]\right)$ and $\mathrm{MC}\left(\mathrm{M}_{\text {difference }}=-4.75, p=0.003,95 \%\right.$ C.I. $\left.[-8.35,-1.15]\right)$ but similarly to $\mathrm{MD}$ $\left(\mathrm{M}_{\text {difference }}=-1.08, p=1.000,95 \%\right.$ C.I. $\left.[-4.92,2.75]\right)$; $\mathrm{MD}$ performed similarly to BC $\left(\mathrm{M}_{\text {difference }}=-2.60, \mathrm{p}=0.344,95 \%\right.$ C.I. $\left.[-6.24,1.03]\right)$ but worse than $\mathrm{MC}\left(\mathrm{M}_{\text {difference }}=-3.67\right.$, $p=0.047,95 \%$ C.I. [-7.31, -0.03]); no differences were found between MC and BC $\left(\mathrm{M}_{\text {difference }}=1.07, p=1.000,95 \%\right.$ C.I. $\left.[-2.32,4.46]\right)$. In $\operatorname{BDS}(F(3,103)=4.722, p<0.004$, partial $\left.\eta^{2}=0.121\right)$, instead, BD performed similarly to $\mathrm{MD}\left(\mathrm{M}_{\text {difference }}=0.59, p=1.000,95 \%\right.$ C.I. $[-2.88,4.07])$, but also to $\mathrm{MC}\left(\mathrm{M}_{\text {difference }}=-2.70, p=0.170,95 \%\right.$ C.I. $\left.[-5.96,0.56]\right)$, and only marginally significantly lower than $\mathrm{BC}\left(\mathrm{M}_{\text {difference }}=-3.13, p=0.067,95 \%\right.$ C.I. [ $\left.\left.-6.40,0.13\right]\right)$. $\mathrm{MD}$ showed the worst performance, scoring lower than $\mathrm{BC}\left(\mathrm{M}_{\text {difference }}=-3.73, p=0.018\right.$, $95 \%$ C.I. [-7.03, -0.42]) and marginally significantly lower than $\mathrm{MC}\left(\mathrm{M}_{\text {difference }}=-3.29\right.$, $p=0.051,95 \%$ C.I. $[-6.60,0.01])$.

\subsubsection{Phonological Awareness}

As shown in Table 4, where the results of the three phonological awareness tasks are reported, the two control groups performed very accurately in nonword repetition and rhyme detection, displaying a lower accuracy in the spoonerisms, similar to what was found in Study 1. The two groups with dyslexia exhibited instead much wider difficulties in all three tasks, and especially in the spoonerisms: in this case, bilingual children with dyslexia were able to provide half of the target items, as opposed to the three quarters of the control groups, but performed slightly better than the monolingual children with dyslexia.

Table 4. Mean accuracy (SDs) of the four groups in the phonological tasks.

\begin{tabular}{cccc}
\hline Group & Nonword Repetition & Rhyme Detection & Spoonerisms \\
\hline MD & $0.85(0.07)$ & $0.89(0.13)$ & $0.41(0.22)$ \\
MC & $0.94(0.03)$ & $0.98(0.05)$ & $0.73(0.18)$ \\
BD & $0.81(0.06)$ & $0.81(0.17)$ & $0.50(0.28)$ \\
BC & $0.93(0.05)$ & $0.97(0.06)$ & $0.75(0.22)$ \\
\hline
\end{tabular}

Notes: $\mathrm{MD}=$ Monolingual children with Dyslexia; $\mathrm{MC}=$ Monolingual Controls; $\mathrm{BD}=$ Bilingual children with Dyslexia; $\mathrm{BC}=$ Bilingual Controls.

These considerations were confirmed by the statistical analysis, reporting significant differences in nonword repetition $\left(F(3,104)=34.93, p<0.001\right.$, partial $\left.\eta^{2}=0.50\right)$; posthoc comparisons with Bonferroni correction revealed that BD performed similarly to MD $\left(\mathrm{M}_{\text {difference }}=-0.04, p=0.145,95 \%\right.$ C.I. $\left.[-0.08,-0.01]\right)$, but significantly worse than BC $\left(\mathrm{M}_{\text {difference }}=-0.12, p<0.001,95 \%\right.$ C.I. $\left.[-0.16,-0.08]\right)$ and $\mathrm{MC}\left(\mathrm{M}_{\text {difference }}=-0.13, p<0.001\right.$, $95 \%$ C.I. $[-0.16,-0.09])$. MD performed worse than both $\mathrm{MC}\left(\mathrm{M}_{\text {difference }}=-0.09, p<0.001\right.$, $95 \%$ C.I. $[-0.13,-0.05])$ and BC $\left(\mathrm{M}_{\text {difference }}=-0.08, p<0.001,95 \%\right.$ C.I. $\left.[-1.22,-0.05]\right) . \mathrm{MC}$ and $\mathrm{BC}$ had an equivalent score $\left(\mathrm{M}_{\text {difference }}=0.01, p=1.000,95 \%\right.$ C.I. $\left.[-0.03,-0.05]\right)$.

Similarly, group was significant in rhyme detection $(F(3,104)=15.26, p<0.001$, partial $\left.\eta^{2}=0.31\right)$ : post-hoc comparisons with Bonferroni correction showed that BD were less skilled than $\mathrm{MC}\left(\mathrm{M}_{\text {difference }}=-0.18, p<0.001,95 \%\right.$ C.I. $\left.[-0.25,-0.10]\right)$ and BC $\left(\mathrm{M}_{\text {difference }}=-0.17, p<0.001,95 \%\right.$ C.I. $\left.[-0.24,-0.09]\right)$, but performed similarly to MD $\left(\mathrm{M}_{\text {difference }}=-0.08, p=0.074,95 \%\right.$ C.I. $\left.\left.[-0.16,-0.00]\right)\right)$. MD performed worse than both MC $\left(\mathrm{M}_{\text {difference }}=-0.10, p=0.009,95 \%\right.$ C.I. $\left.[-0.18,-0.02]\right)$ and BC $\left(\mathrm{M}_{\text {difference }}=-0.09, p=0.026\right.$, $95 \%$ C.I. $[-0.17,-0.01]) ;$ no differences were found between $\mathrm{MC}$ and BC $\left(\mathrm{M}_{\text {difference }}=0.01\right.$, $p=1.000,95 \%$ C.I. $[-0.07,0.09])$.

Significant differences were also found in the spoonerism task $(F(3,104)=14.66$, $p<0.001$, partial $\left.\eta^{2}=0.30\right)$ : post-hoc multiple comparisons with Bonferroni correction 
showed that BD scored similarly to $\mathrm{MD}\left(\mathrm{M}_{\text {difference }}=0.09, p=0.981,95 \%\right.$ C.I. [ -0.08 , $0.27])$, but worse than $\mathrm{MC}\left(\mathrm{M}_{\text {difference }}=-0.23, p=0.002,95 \%\right.$ C.I. $\left.[-0.40,0.07]\right)$ and BC $\left(\mathrm{M}_{\text {difference }}=-0.24, p=0.001,95 \%\right.$ C.I. $\left.[-0.41,0.08]\right)$, as well as $\mathrm{MD}$, who underperformed $\mathrm{MC}\left(\mathrm{M}_{\text {difference }}=-0.32, p<0.001,95 \%\right.$ C.I. $\left.[-0.49,-0.16]\right)$ and BC $\left(\mathrm{M}_{\text {difference }}=-0.33\right.$, $p<0.001,95 \%$ C.I. $[-0.503,-0.170]) ; \mathrm{MC}$ and BC, instead, did not differ $\left(\mathrm{M}_{\text {difference }}=-0.01\right.$, $p=1.000,95 \%$ C.I. $[-0.17,0.14])$.

\subsubsection{Correlations}

Correlational analyses separated for each group were run to explore the relationship between vocabulary (PPVT-R), the two working memory tasks (FDS and BDS) and the three phonological awareness tasks.

As for the nonword repetition task, in both groups of children with dyslexia we found only one significant positive correlation between accuracy and phonological memory, as measured by the FDS (BD: $r(24)=0.46, p=0.023$; MD: $r(23)=0.52, p=0.012$ ). For $\mathrm{MC}$, instead, performance in nonword repetition was correlated with both FDS $(r(30)=0.42$, $p=0.022)$, BDS $(\mathrm{r}(30)=0.57, p=0.010)$ and spoonerisms $(r(30)=0.464, p=0.010)$, whereas for $\mathrm{BC}$ nonword repetition correlated only with the other two phonological tasks, rhyme detection $(r(30)=0.52, p=0.003)$ and spoonerisms $(r(30)=0.59, p=0.001)$.

Concerning the rhyme detection task, again only FDS significantly correlated with performance for the two groups with dyslexia (BD: $r(24)=0.41, p=0.048$; MD: $r(23)=0.423$, $p=0.045)$. Accuracy in the task only correlated with spoonerisms $(r(30)=0.47, p=0.010)$ and vocabulary $(r(30)=0.36, p=0.048)$ for $\mathrm{MC}$, and with both phonological tasks for BC (spoonerisms: $r(30)=0.40, p=0.27$; nonword repetition: $r(30)=0.52, p=0.003$ ).

Finally, interesting results were found for the most difficult task, the spoonerism, in which accuracy correlated only with FDS in BD $(r(24)=0.441, p=0.031)$, and only with BDS in MD $(r(23)=0.63, p=0.001)$. As for BC, instead, accuracy correlated with FDS $(r(30)=0.65, p<0.001)$, BDS $(r(30)=0.68, p<0.001$, nonword repetition $(r(30)=0.59$, $p=0.001)$ and rhyme detection $(r(30)=0.40, p=0.027)$. In MC, accuracy correlated with both phonological tasks (nonword repetition: $r(30)=0.46, p=0.010$; rhyme detection: $r(30)=0.47, p=0.010)$ and, as for memory, only with BDS $(r(30)=0.39, p=0.035)$.

No other significant correlations, including vocabulary, were found.

\section{Discussion}

The main purpose of this research was that of exploring phonological awareness skills across different groups of school-aged children, investigating whether and how performance was influenced by the presence of bilingualism, of a diagnosis of dyslexia and of the interaction between these two dimensions. To this aim, we developed and administered three different tasks, respectively assessing nonword repetition, rhyme detection and spoonerisms, that were selected since they permit us to tackle different aspects of the complex and multifaceted construct of phonological awareness.

As discussed in the introduction, individuals with dyslexia have generally been found impaired in these tasks, whereas studies assessing PA abilities in bilingual children have yielded contrasting results. More particularly, evidence of a bilingual advantage related to the transfer of salient or complex features from the first to the second language has been counterbalanced by an absence of differences between monolinguals and bilinguals or even evidence of a bilingual disadvantage.

To further explore the effects of bilingualism in this domain, in Study 1, we compared the performance in nonword repetition, rhyme detection and spoonerisms of a group of 10-year-old Italian monolingual children and two groups of bilingual children, with 7 years of exposure to L2 Italian and having as an L1 either Romanian or Arabic, two languages that are respectively similar and distant from Italian in terms of phonological features. Results interestingly showed that both bilingual groups performed similarly to the two monolingual groups, with no differences related to their L1, thus providing no evidence for advantages or disadvantages related to bilingualism in the phonological 
domain. This result can be explained by capitalizing on the relative simplicity of the Italian phonotactics, which is quite easily acquired, after sufficient exposure, by children having both a phonologically similar L1, as in the case of Romanian, and a different one, as in the case of Arabic.

Based on these results, the purpose of Study 2 was to determine how bilingualism and dyslexia interact in the very same three tasks. Consistently with the literature reviewed above, we found that children with dyslexia, both monolingual and bilingual, significantly underperformed controls in the three tasks, struggling in particular in the spoonerism, where they were able to provide only half of the required items, in contrast with the much higher accuracy of the control children. As in Study 1, instead, no effects related to bilingualism were found, since both groups of bilinguals performed similarly to their monolingual peers. These results confirm on the one side that the deficits characterizing dyslexia are particularly marked when both good phonological skills and memory resources are required, and on the other side they indicate that bilingualism does not affect performance.

This warrants an important indication for all parents, educators and health professionals that worry about possible negative effects of bilingualism in dyslexia: the data of this study, in line with what is reported by other research in different linguistic domains (Vender et al. 2018a, 2018b, 2020, 2021), indicate that being bilingual does not exacerbate the difficulties at the core of dyslexia, but it could on the contrary be even beneficial for the many advantages that it can bring at the linguistic, cognitive and cultural level.

Although no differences related to bilingualism were reported in the two studies presented here, the correlational analyses conducted in Study 2 prompt some interesting considerations suggesting that different processes might be at play in the four groups of children considered. The first notable result concerns the correlations found in the spoonerism task, where a difference between monolinguals and bilinguals in the memory processes involved in the task clearly emerged. In both groups of monolinguals, indeed, there was a significant correlation between performance and the backward digit span task, indicating that accuracy was higher in those children with higher working memory abilities, in the sense of both phonological memory and manipulation skills (respectively resting on the Phonological Loop and on the Central Executive, in Baddeley 2001 terms). Conversely, no such correlation was found in the bilingual children with dyslexia, where on the contrary accuracy correlated with the forward digit span task, in which only phonological memory is required, whereas both forward and backward digit span were positively correlated with performance. This seems to suggest that for bilingual children being able to accurately swap the initial sound of two given words is not specifically a matter of manipulation and attention abilities, but what seems to make the difference is phonological memory per se, that is the segmentation ability that permits to accurately identify and maintain in memory the sounds composing the relevant words. It appears thus that while monolinguals exploit their manipulation abilities to perform the spoonerism task, bilinguals capitalize more on their sensitivity to the phonological structure of the words, much in the spirit of the Structural Sensitivity Theory (Kuo and Anderson 2010) according to which bilinguals, having access to two languages, are able to form a more solid representation of language structures at an abstract level. Our results indicate indeed that those bilinguals who have a better functioning phonological memory are also more skilled in performing the spoonerism tasks. Moreover, the fact that bilinguals have a poorer receptive vocabulary than monolinguals found in both Study 1 and Study 2 (and consistently with Bialystok et al. 2010, among many others) is notably not related to their performance in PA tasks. The only significant correlation between phonological tasks and vocabulary was indeed found in rhyme detection, although it was limited to the monolingual typically developing children, where participants showing better receptive vocabulary also performed more accurately in identifying rhymes.

The results of the correlational analyses offer another interesting consideration, juxtaposing in this case children with and without dyslexia: in the two groups of typically developing children, indeed, the results of the three PA tasks were highly correlated to 
each other, indicating that children who were highly skilled in one task also obtained high scores in the others. This was not found instead for the two groups with dyslexia, for whom no correlations were found among the three tasks. In both nonword repetition and rhyme detection, indeed, the performance of both groups was only significantly related to phonological memory (i.e., FDS), thus confirming the extent of the phonological anomalies characterizing dyslexia.

A final observation that is worth mentioning concerns the results of the reading tasks that were administered as preliminary measures: in both studies we found that bilingual typically developing children performed similarly to their monolingual peers in all the parameters considered, including word and nonword reading speed and accuracy, in spite of their poorer receptive vocabulary. On the other hand, bilingual children with dyslexia, besides showing a significant impairment in all reading measures, were interestingly faster than monolingual children with dyslexia, indicating once again that bilingualism does not seem to aggravate the difficulties related to this disorder, as is often erroneously believed, but may instead show a significant advantage with respect to monolinguals.

\section{Conclusions}

The two studies presented in this paper were developed to assess the phonological awareness in Italian of monolingual and bilingual school-aged children, with and without a diagnosis of developmental dyslexia. The results of Study 1 suggested that L2 Italian children performed at the same level as the monolingual Italian children in nonword repetition, rhyme detection and spoonerisms, independently on the L1 considered, Romanian or Arabic, and thus on the level of phonological similarity or distance between L1 and L2.

Similarly, in Study 2 we found no effect of bilingualism in the same phonological awareness tasks, both in typically developing children and in children with dyslexia; besides confirming that children with dyslexia exhibited severe difficulties in the three tasks, and especially in the spoonerism, i.e., the most expensive in terms of memory resources, our results indicate that being bilingual does not impose a further burden on the phonological abilities of children with reading impairments. On the contrary, monolingual and bilingual children with dyslexia showed similar accuracy levels, although their performance in phonological awareness tasks might depend on different processes, as revealed by the correlational analyses performed in Study 2 .

A limitation of this research lies in the small sample size of the typically developing bilingual children who took part in Study 1 and in the fact that the bilingual children included in Study 2, both with and without dyslexia, had heterogeneous L1s. Although the results of Study 1 indicate an absence of L1 effects on phonological skills in L2 Italian, further research with a larger sample of participants and groups of bilingual children with dyslexia speaking the same L1 could provide more solid data.

Given the importance of phonological skills in the children's linguistic and literacy achievements, we believe that these results can have important practical and pedagogical implications: on the one hand, they indicate that bilingualism should always be encouraged, also in children suffering from specific linguistic or literacy disorders such as dyslexia. The finding that bilinguals with dyslexia performed similarly to their monolingual peers in the domain which is more detrimentally affected in this disorder should reassure us of the fact that speaking another language will not exacerbate the difficulties of children with reading disorders. On the other hand, our results indicate that an early assessment of the children's phonological abilities is desirable and recommended to define their linguistic profile more precisely as well as to identify possible language and reading disorders like dyslexia in a more timely and effective way.

Author Contributions: Conceptualization, M.V. and C.M.; methodology, M.V.; formal analysis, M.V. and C.M.; data curation, M.V.; writing-original draft preparation, M.V. and C.M.; writing-review and editing, M.V. and C.M. For academic purposes, C.M. takes responsibility for Sections 1, 1.1 and 1.2, while M.V. takes responsibility for Sections 1.3 and 2-5. All authors have read and agreed to the published version of the manuscript. 
Funding: The research leading to these results has received funding from the European Union's Seventh Framework Programme for research, technological development and demonstration under grant agreement $n^{\circ} 613465$.

Institutional Review Board Statement: The study was conducted according to the guidelines of the Declaration of Helsinki and approved by the Ethics Committee of the Department of Neurosciences, Biomedicine and Movement Sciences of the University of Verona (date of approval 10 July 2015).

Informed Consent Statement: Informed written consent was obtained from the parents of all children involved in the study.

Data Availability Statement: The data presented in this study are available on request from the corresponding author.

Acknowledgments: We sincerely thank all the children who took part to this research and to their families, the Azienda Provinciale per i Servizi Sanitari-Neuropsichiatria Infantile (Trento), and to the schools and teachers who helped in recruiting the subjects (Istituti Comprensivi Bassa Anaunia, Cles, Revò, Taio, Tuenno (TN), Scuola Primaria A. Massalongo (VR). We also thank the organizers and participants of ISMBS 2019 (27-30 August 2019, Greece), where a first version of this work was presented.

Conflicts of Interest: The authors declare no conflict of interest.

\section{References}

Adlard, Alan, and Valerie Hazan. 1998. Speech Perception in Children with Specific Reading Difficulties (Dyslexia). The Quarterly Journal of Experimental Psychology A: Human Experimental Psychology 51A: 153-77. [CrossRef]

Baddeley, Alan D. 2001. Is Working Memory Still Working? American Psychologist 56: 851-64. [CrossRef] [PubMed]

Belacchi, Carmen, Teresa Gloria Scalisi, Eleonora Cannoni, and Cesare Cornoldi. 2008. CPM—Coloured Progressive Matrices. Standardizzazione Italiana. Florence: Giunti OS, Organizzazioni Speciali.

Beneventi, Harald, Finn Egil Tønnessen, Lars Ersland, and Kenneth Hugdahl. 2010. Executive Working Memory Processes in Dyslexia: Behavioral and FMRI Evidence: Working Memory Deficit in Dyslexia. Scandinavian Journal of Psychology 51: 192-202. [CrossRef]

Bialystok, Ellen, Gigi Luk, Kathleen F. Peets, and Sujin Yang. 2010. Receptive Vocabulary Differences in Monolingual and Bilingual Children. Bilingualism: Language and Cognition 13: 525-31. [CrossRef] [PubMed]

Bialystok, Ellen, Kathleen F. Peets, and Sylvain Moreno. 2014. Producing Bilinguals through Immersion Education: Development of Metalinguistic Awareness. Applied Psycholinguistics 35: 177-91. [CrossRef]

Bialystok, Ellen, Shilpi Majumder, and Michelle M. Martin. 2003. Developing Phonological Awareness: Is There a Bilingual Advantage? Applied Psycholinguistics 24: 27-44. [CrossRef]

Bialystok, Ellen. 1986. Factors in the Growth of Linguistic Awareness. Child Development 57: 498. [CrossRef]

Bialystok, Ellen. 2001. Bilingualism in Development: Language, Literacy, and Cognition, 1st ed. Cambridge: Cambridge University Press.

Blachman, Benita A. 1991. Getting Ready to Read: Learning How Print Maps to Speech. In The Language Continuum: From Infancy to Literacy. Edited by James F. Kavanagh. Parkton: York Press, pp. 41-62.

Blachman, Benita A. 2000. Phonological Awareness. In Handbook of Reading Research, Vol. III. Edited by Michael L. Kamil, Peter B. Mosenthal, P. David Pearson and Rebecca Barr. Mahwah: Lawrence Erlbaum Associates Publishers, pp. 483-502.

Bradley, Lynette, and Peter E. Bryant. 1983. Categorizing Sounds and Learning to Read-A Causal Connection. Nature 301: 419-21. [CrossRef]

Bradley, Lynette, and Peter E. Bryant. 1978. Difficulties in Auditory Organisation as a Possible Cause of Reading Backwardness. Nature 271: 746-47. [CrossRef] [PubMed]

Branum-Martin, Lee, Sha Tao, and Sarah Garnaat. 2015. Bilingual Phonological Awareness: Reexamining the Evidence for Relations within and across Languages. Journal of Educational Psychology 107: 111-25. [CrossRef]

Branum-Martin, Lee, Sha Tao, Sarah Garnaat, Ferenc Bunta, and David J. Francis. 2012. Meta-Analysis of Bilingual Phonological Awareness: Language, Age, and Psycholinguistic Grain Size. Journal of Educational Psychology 104: 932-44. [CrossRef]

Bruck, Maggie, and Fred Genesee. 1995. Phonological Awareness in Young Second Language Learners. Journal of Child Language 22: 307-24. [CrossRef]

Bruck, Maggie. 1992. Persistence of Dyslexics' Phonological Awareness Deficits. Developmental Psychology 28: 874-86. [CrossRef]

Bryant, Peter E., Morag MacLean, Lynette Bradley, and J. Crossland. 1990. Rhyme and Alliteration, Phoneme Detection, and Learning to Read. Developmental Psychology 26: 429-38. [CrossRef]

Campbell, Ruth, and Efisia Sais. 1995. Accelerated Metalinguistic (Phonological) Awareness in Bilingual Children. British Journal of Developmental Psychology 13: 61-68. [CrossRef]

Knoop-van Campen, Carolien A. N., Eliane Segers, and Ludo Verhoeven. 2018. How Phonological Awareness Mediates the Relation between Working Memory and Word Reading Efficiency in Children with Dyslexia. Dyslexia 24: 156-69. [CrossRef] [PubMed] 
Catts, Hugh W., Suzanne M. Adlof, Tiffany P. Hogan, and Susan Ellis Weismer. 2005. Are Specific Language Impairment and Dyslexia Distinct Disorders? Journal of Speech, Language, and Hearing Research 48: 1378-96. [CrossRef]

Chen, Xi, Richard C. Anderson, Wenling Li, Meiling Hao, Xinchun Wu, and Hua Shu. 2004. Phonological Awareness of Bilingual and Monolingual Chinese Children. Journal of Educational Psychology 96: 142-51. [CrossRef]

Cilibrasi, Luca, Vesna Stojanovik, Tom Loucas, and Patricia Riddell. 2018. The role of noninitial clusters in the Children's Test of Nonword Repetition: Evidence from children with language impairment and typically developing children. Dyslexia 4: 322-35. [CrossRef]

Couture, Ashley E., and Rebecca J. McCauley. 2000. Phonological Working Memory in Children with Phonological Impairment. Clinical Linguistics \& Phonetics 14: 499-517.

de Bree, Elise, Frank Wijnen, and Ellen Gerrits. 2010. Non-Word Repetition and Literacy in Dutch Children at-Risk of Dyslexia and Children with SLI: Results of the Follow-up Study. Dyslexia 16: 36-44. [CrossRef] [PubMed]

Denckla, Martha Bridge, and Rita G. Rudel. 1976. Rapid 'Automatized' Naming (R.A.N.): Dyslexia Differentiated from Other Learning Disabilities. Neuropsychologia 14: 471-79. [CrossRef]

Desroches, Amy S., Marc F. Joanisse, and Erin K. Robertson. 2006. Specific Phonological Impairments in Dyslexia Revealed by Eyetracking. Cognition 100: B32-42. [CrossRef] [PubMed]

Diaz, Rafael M. 1985. Bilingual Cognitive Development: Addressing Three Gaps in Current Research. Child Development 56: $1376-88$. [CrossRef]

Dollaghan, Chris, and Thomas F. Campbell. 1998. Nonword Repetition and Child Language Impairment. Journal of Speech, Language, and Hearing Research 41: 1136-46. [CrossRef]

Dunn, Lloyd M., and Leota M. Dunn. 2000. PEABODY—Test di Vocabolario Recettivo-P.P.V.T.-R. Peabody Picture Vocabulary TestRevised-Test Psicolinguistico. Adattamento italiano e standardizzazione a cura di: Giacomo Stella-Claudia Pizzioli-Patrizio E. Tressoldi. Torino: Omega Edizioni.

Durgunoğlu, Aydin Y., William E. Nagy, and Barbara J. Hancin-Bhatt. 1993. Cross-Language Transfer of Phonological Awareness. Journal of Educational Psychology 85: 453-65. [CrossRef]

Eden, Guinevere F., Karen M. Jones, Katherine Cappell, Lynn Gareau, Frank B. Wood, Thomas A. Zeffiro, Nicole A. E. Dietz, John A. Agnew, and D. Lynn Flowers. 2004. Neural Changes following Remediation in Adult Developmental Dyslexia. Neuron 44: 411-422. [CrossRef]

Elbro, Carsten. 1996. Early Linguistic Abilities and Reading Development: A Review and a Hypothesis. Reading and Writing 8: 453-85. [CrossRef]

Erdos, Caroline, Fred Genesee, Robert Savage, and Corinne Haigh. 2014. Predicting Risk for Oral and Written Language Learning Difficulties in Students Educated in a Second Language. Applied Psycholinguistics 35: 371-98. [CrossRef]

Galambos, Silvia J., and Susan Goldin-Meadow. 1990. The Effects of Learning Two Languages on Levels of Metalinguistic Awareness. Cognition 34: 1-56. [CrossRef]

Galatà, Vincenzo, Giulia Angonese, and Claudio Zmarich. 2020. Italian as L2 in Romanian Pre-Schoolers. Evidence from a Perception and Production Task. In Fattori Sociali e Biologici Nella Variazione Fonetica-Social and Biological Factors in Speech Variation. Edited by Chiara Bertini, Chiara Celata, Giovanna Lenoci, Chiara Meluzzi and Irene Ricci. Milano: Officinaventuno, pp. $257-80$.

Gathercole, Susan E., Catherine S. Willis, Alan D. Baddeley, and Hazel Emslie. 1994. The Children's Test of Nonword Repetition: A test of phonological working memory. Memory 2: 103-27. [CrossRef]

Girbau, Dolors, and Richard G. Schwartz. 2008. Phonological Working Memory in Spanish-English Bilingual Children with and without Specific Language Impairment. Journal of Communication Disorders 41: 124-45. [CrossRef] [PubMed]

Goswami, Usha. 1999. Causal connections in beginning reading: The importance of rhyme. Journal of Research in Reading 22: 217-40. [CrossRef]

Grivol, Marcia Aparecida, and Simone Rocha de Vasconcellos Hage. 2011. Phonological Working Memory: A Comparative Study between Different Age Groups. Jornal Da Sociedade Brasileira de Fonoaudiologia 23: 245-51. [CrossRef]

Jeffries, Sharman, and John Everatt. 2004. Working Memory: Its Role in Dyslexia and Other Specific Learning Difficulties. Dyslexia 10: 196-214. [CrossRef]

Joanisse, Marc F., Franklin R. Manis, Patricia Keating, and Mark S. Seidenberg. 2000. Language Deficits in Dyslexic Children: Speech Perception, Phonology, and Morphology. Journal of Experimental Child Psychology 77: 30-60. [CrossRef] [PubMed]

Kamhi, Alan G., and Hugh W. Catts. 1986. Toward an Understanding of Developmental Language and Reading Disorders. The Journal of Speech and Hearing Disorders 51: 337-47. [CrossRef] [PubMed]

Kohnert, Kathryn, Jennifer Windsor, and Dongsun Yim. 2006. Do Language-Based Processing Tasks Separate Children with Language Impairment from Typical Bilinguals? Learning Disabilities Research and Practice 21: 19-29. [CrossRef]

Kuo, Li-Jen, and Richard C. Anderson. 2010. Beyond Cross-Language Transfer: Reconceptualizing the Impact of Early Bilingualism on Phonological Awareness. Scientific Studies of Reading 14: 365-85. [CrossRef]

Landerl, Karin, Heinz Wimmer, and Uta Frith. 1997. The Impact of Orthographic Consistency on Dyslexia: A German-English Comparison. Cognition 63: 315-34. [CrossRef]

Landerl, Karin, and Heinz Wimmer. 2000. Deficits in Phoneme Segmentation Are Not the Core Problem of Dyslexia: Evidence from German and English Children. Applied Psycholinguistics 21: 243-62. [CrossRef] 
Manis, Franklin R., Catherine McBride-Chang, Mark S. Seidenberg, Patricia Keating, Lisa M. Doi, Benjamin Munson, and Alan Petersen. 1997. Are Speech Perception Deficits Associated with Developmental Dyslexia? Journal of Experimental Child Psychology 66: 211-35. [CrossRef]

Mann, Virginia. 1991. Phonological awareness and early reading ability: One perspective. In Phonological Awareness in Reading: The Evolution of Current Perspectives. Edited by Diane J. Sawyer and Barbara J. Fox. New York: Springer-Verlag, pp. 191-215.

Melby-Lervåg, Monica, and Arne Lervåg. 2011. Cross-Linguistic Transfer of Oral Language, Decoding, Phonological Awareness and Reading Comprehension: A Meta-Analysis of the Correlational Evidence. Journal of Research in Reading 34: 114-35. [CrossRef]

Melloni, Chiara, and Maria Vender. 2020. 13. Phonological Processing and Nonword Repetition: A Critical Tool for the Identification of Dyslexia in Bilingualism. An Anthology of Bilingual Child Phonology. Bristol: Multilingual Matters.

Messer, Marielle H., Paul P. M. Leseman, Jan Boom, and Aziza Y. Mayo. 2010. Phonotactic Probability Effect in Nonword Recall and Its Relationship with Vocabulary in Monolingual and Bilingual Preschoolers. Journal of Experimental Child Psychology 105: 306-23. [CrossRef]

Mundy, Ian R., and Julia M. Carroll. 2012. Speech Prosody and Developmental Dyslexia: Reduced Phonological Awareness in the Context of Intact Phonological Representations. Journal of Cognitive Psychology 24: 560-81. [CrossRef]

Muter, Valerie, Charles Hulme, Margaret Snowling, and Sara Taylor. 1998. Segmentation, not rhyming, predicts early progress in learning to read. Journal of Experimental Child Psychology 71: 3-27. [CrossRef]

Paulesu, Eraldo, Eamon McCrory, Ferruccio Fazio, Lorena Menoncello, Nicola Brunswick, Stefano F. Cappa, Maria Cotelli, Giuseppe Cossu, F. Corte, Maria Luisa Lorusso, and et al. 2000. A Cultural Effect on Brain Function. Nature Neuroscience 3: 91-96. [CrossRef] [PubMed]

Pickering, Sue, and Sue Gathercole. 2001. Working Memory Test Battery for Children (WMTB-C): Manual. London: Pearson Assessment.

Ramus, Franck, and Gayaneh Szenkovits. 2008. What Phonological Deficit? Quarterly Journal of Experimental Psychology 61: 129-41. [CrossRef] [PubMed]

Ramus, Franck, and Merav Ahissar. 2012. Developmental Dyslexia: The Difficulties of Interpreting Poor Performance, and the Importance of Normal Performance. Cognitive Neuropsychology 29: 104-22. [CrossRef] [PubMed]

Ramus, Franck, Chloe R. Marshall, Stuart Rosen, and Heather K. J. van der Lely. 2013. Phonological Deficits in Specific Language Impairment and Developmental Dyslexia: Towards a Multidimensional Model. Brain: A Journal of Neurology 136, Pt 2: 630-45. [CrossRef] [PubMed]

Ramus, Franck, Elizabeth Pidgeon, and Uta Frith. 2003. The Relationship between Motor Control and Phonology in Dyslexic Children: Motor Control and Phonology in Dyslexic Children. Journal of Child Psychology and Psychiatry 44: 712-22. [CrossRef] [PubMed]

Raven, John Carlyle, John H. Court, and Jean Raven. 1998. Raven Manual, Section 1 (General Overview) and Section 2 (Coloured Progressive Matrices). Oxford: Oxford Psychologist Press.

Rubin, Hyla, and Anne Turner. 1989. Linguistic Awareness Skills in Grade One Children in a French Immersion Setting. Reading and Writing 1: 73-86. [CrossRef]

Sartori, Giuseppe, Remo Job, and Patrizio E. Tressoldi. 2007. DDE-2. Batteria per La Valutazione Della Dislessia e Della Disortografia Evolutiva-2. Firenze: Giunti OS, Organizzazioni Speciali.

Savin, Harris B. 1972. What the Child Knows about Speech When He Starts to Learn to Read. In Language by Ear and by Eye: The Relationships between Speech and Reading. Edited by James F. Kavanagh and Ignatius G. Mattingly. Cambridge: MIT Press, pp. 319-26.

Snowling, Margaret J. 2000. Dyslexia, 2nd ed. Malden: Blackwell Publishing.

Snowling, Margaret J., Nata Goulandris, and Neil Defty. 1996. A Longitudinal Study of Reading Development in Dyslexic Children. Journal of Educational Psychology 88: 653-69. [CrossRef]

Stanovich, Keith E. 1988. Explaining the Differences between the Dyslexic and the Garden-Variety Poor Reader: The Phonological-Core Variable-Difference Model. Journal of Learning Disabilities 21: 590-604. [CrossRef] [PubMed]

Stanovich, Keith E. 1986. Matthew Effects in Reading: Some Consequences of Individual Differences in the Acquisition of Literacy. Reading Research Quarterly 21: 360-407. [CrossRef]

Stella, Vitantonio, and Remo Job. 2001. Le Sillabe PD/DPSS. Una Base Di Dati Sulla Frequenza Dell'italiano Scritto. Giornale Italiano Di Psicologia 3: 633-39.

Szenkovits, Gayaneh, and Franck Ramus. 2005. Exploring Dyslexics' Phonological Deficit I: Lexical vs Sub-Lexical and Input vs Output Processes. Dyslexia 11: 253-68. [CrossRef]

Tamburelli, Marco, Eirini Sanoudaki, Gary Jones, and Michelle Sowinska. 2015. Acceleration in the Bilingual Acquisition of Phonological Structure: Evidence from Polish-English Bilingual Children. Bilingualism: Language and Cognition 18: 713-25. [CrossRef]

Thordardottir, Elin, and Myrto Brandeker. 2013. The Effect of Bilingual Exposure versus Language Impairment on Nonword Repetition and Sentence Imitation Scores. Journal of Communication Disorders 46: 1-16. [CrossRef] [PubMed]

Tijms, Jurgen. 2004. Verbal Memory and Phonological Processing in Dyslexia. Journal of Research in Reading 27: 300-10. [CrossRef]

Topoliceanu, Harieta. 2011. Italiano e rumeno a confronto: analisi di alcuni problemi di apprendimento dell'italiano da parte dei madrelingua rumeni. Philologica Jassyensia VII: 243-55.

Unsworth, Sharon, Froso Argyri, Leonie Cornips, Aafke Hulk, Antonella Sorace, and Ianthi Tsimpli. 2014. The Role of Age of Onset and Input in Early Child Bilingualism in Greek and Dutch. Applied Psycholinguistics 35: 765-805. [CrossRef]

Vellutino, Frank R. 1979. Dyslexia: Theory and Research. Cambridge: The MIT Press. 
Vender, Maria, Denis Delfitto, and Chiara Melloni. 2020. How Do Bilingual Dyslexic and Typically Developing Children Perform in Nonword Repetition? Evidence from a Study on Italian L2 Children. Bilingualism: Language and Cognition 23: 884-96. [CrossRef]

Vender, Maria, Maria Garraffa, Antonella Sorace, and Maria Teresa Guasti. 2016. How Early L2 Children Perform on Italian Clinical Markers of SLI: A Study of Clitic Production and Nonword Repetition. Clinical Linguistics \& Phonetics 30: 150-69.

Vender, Maria, Shenai Hu, Federica Mantione, Denis Delfitto, and Chiara Melloni. 2018a. The Production of Clitic Pronouns: A Study on Bilingual and Monolingual Dyslexic Children. Frontiers in Psychology 9: 2301. [CrossRef]

Vender, Maria, Denis Delfitto, and Chiara Melloni. 2018b. Clitic production and bilingualism: When exposure matters. Languages 3: 22. [CrossRef]

Vender, Maria, Shenai Hu, Federica Mantione, Silvia Savazzi, Denis Delfitto, and Chiara Melloni. 2021. Inflectional morphology: Evidence for an advantage of bilingualism in dyslexia. International Journal of Bilingual Education and Bilingualism 24: 155-72. [CrossRef]

Vender, Maria. 2017. Disentangling Dyslexia. Bern: Peter Lang CH.

Wagner, Richard K., and Joseph K. Torgesen. 1987. The Nature of Phonological Processing and Its Causal Role in the Acquisition of Reading Skills. Psychological Bulletin 101: 192-212. [CrossRef]

Walton, Diana, and Peter Brooks. 1995. The Spoonerism Test. Educational and Child Psychology 12: 50-52.

Watson, Janet C. E. 2007. The Phonology and Morphology of Arabic. The Phonology of the World's Languages. Oxford: Oxford University Press.

Wolf, Maryanne, and Patricia G. Bowers. 2000. Naming-Speed Processes and Developmental Reading Disabilities: An Introduction to the Special Issue on the Double-Deficit Hypothesis". Journal of Learning Disabilities 33: 322-24. [CrossRef]

World Health Organisation. 1993. ICD-10 Classification of Mental Health and Behavioural Disorders: Diagnostic Criteria for Research. Geneva: World Health Organisation.

World Health Organization. 2004. International Statistical Classification of Diseases and Health Related Problems (ICD_10), 2nd ed. Geneva: World Health Organisation.

Yelland, Gregory W., Jacinta Pollard, and Anthony Mercuri. 1993. The Metalinguistic Benefits of Limited Contact with a Second Language. Applied Psycholinguistics 14: 423-44. [CrossRef] 